\title{
Mutational spectrum of the APC and MUTYH genes and genotype-phenotype correlations in Brazilian FAP, AFAP, and MAP patients
}

\author{
Giovana Tardin Torrezan ${ }^{1}$, Felipe Cavalcanti Carneiro da Silva' ${ }^{1}$ Érika Maria Monteiro Santos ${ }^{2,3}$, \\ Ana Cristina Victorino Krepischi ${ }^{2,4}$, Maria Isabel Waddington Achatz ${ }^{2,5}$, Samuel Aguiar Junior ${ }^{3}$, \\ Benedito Mauro Rossi $6^{*}$ and Dirce Maria Carraro $1,2,7^{*}$
}

\begin{abstract}
Background: Patients with multiple colorectal adenomas are currently screened for germline mutations in two genes, APC and MUTYH. APC-mutated patients present classic or attenuated familial adenomatous polyposis (FAP/ AFAP), while patients carrying biallelic MUTYH mutations exhibit MUTYH-associated polyposis (MAP). The spectrum of mutations as well as the genotype-phenotype correlations in polyposis syndromes present clinical impact and can be population specific, making important to obtain genetic and clinical data from different populations.

Methods: DNA sequencing of the complete coding region of the APC and MUTYH genes was performed in 23 unrelated Brazilian polyposis patients. In addition, mutation-negative patients were screened for large genomic rearrangements by multiplex ligation-dependent probe amplification, array-comparative genomic hybridization, and duplex quantitative PCR. Biallelic MUTYH mutations were confirmed by allele-specific PCR. Clinical data of the index cases and their affected relatives were used to assess genotype-phenotype correlations.

Results: Pathogenic mutations were identified in 20 of the 23 probands (87\%): 14 in the APC gene and six in the MUTYH gene; six of them (30\%) were described for the first time in this series. Genotype-phenotype correlations revealed divergent results compared with those described in other studies, particularly regarding the extent of polyposis and the occurrence of desmoid tumors in families with mutations before codon 1444 (6/8 families with desmoid).

Conclusions: This first comprehensive investigation of the APC and MUTYH mutation spectrum in Brazilian polyposis patients showed a high detection rate and identified novel pathogenic mutations. Notably, a significant number of $A P C$-positive families were not consistent with the predicted genotype-phenotype correlations from other populations.
\end{abstract}

Keywords: APC, MUTYH, Genotype-phenotype, Mutation screening, Polyposis

\section{Background}

Patients with multiple colorectal adenomas are screened for germline mutations in two distinct genes, $A P C$ and $M U T Y H$. According to the polyp number and age of onset, the phenotype of $A P C$-mutated patients can be classified as classical familial adenomatous polyposis (FAP:

\footnotetext{
* Correspondence: rossibm@gmail.com; dirce.carraro@cipe.accamargo.org.br ${ }^{6}$ Barretos Cancer Hospital, Pio XII Foundation, Rua Dona Adma Jafet 74 cj. 145, CEP: 01308-050, São Paulo, SP, Brazil

'Laboratory of Genomics and Molecular Biology, A. C. Camargo Hospital, São Paulo, SP, Brazil

Full list of author information is available at the end of the article
}

more than 100 polyps, early onset) or attenuated FAP (AFAP: fewer than 100 polyps with later onset) [1-3]. $M U T Y H$ biallelic mutation carriers usually present 10 to 100 polyps and are categorized as having $M U T Y H$-associated polyposis (MAP) [4].

FAP/AFAP (OMIM \#175100) is a dominantly inherited colorectal cancer $(\mathrm{CRC})$ predisposing syndrome [1,2] caused by mutations in the tumor suppressor gene adenomatous polyposis coli $(A P C)$. The encoded APC protein controls $\beta$-catenin turnover in the Wnt pathway $[5,6]$. Besides colonic polyposis and colorectal cancer,

\section{Biomed Central}


individuals with FAP can present a number of benign extracolonic features, including multiple osteomas, epidermoid cysts, desmoid tumors, and congenital hypertrophy of the retinal pigment epithelium [2]. Over 1100 different pathogenic $A P C$ mutations have been reported to date in the Leiden Open Variation Database (http:// www.lovd.nl/2.0/), the majority of them being nonsense mutations or small insertions or deletions that lead to a truncated protein. Mutations causing AFAP have been reported to occur mainly in three regions of $A P C$ : at the $5^{\prime}$ end (the first five exons), in the alternatively spliced region of exon 9, or at the $3^{\prime}$ end (after codon 1580) [7-9].

MAP (OMIM \#608456) is a recessively inherited syndrome caused by biallelic mutations in the mutY homolog $(M U T Y H)$ gene that maps to chromosome 1p34.1 [4]. MUTYH encodes a DNA glycosylase that plays a key role in the base excision repair pathway by removing mispaired bases caused by the oxidation product 8-oxoG [4]. Nearly 300 different sequence variants have been identified in this gene (LOVD Mutation Database), including about 80 pathogenic mutations distributed throughout the gene at positions corresponding to different functional domains of the encoded protein [10]. In contrast to $A P C$ pathogenic variants, which mostly result in a truncated or absent protein, most MUTYH pathogenic variants are missense substitutions and only a minority are splice site or truncating mutations [11].

With regard to clinical features, most MUTYH-mutated patients present 10 to 100 colorectal adenomas, usually with later onset compared with FAP patients $[4,12,13]$. MUTYH mutation carriers represent approximately $7.5 \%$ of patients with more than 100 adenomas without an $A P C$ mutation, $40 \%$ of all patients with $10-100$ polyps, and $0.3-1.7 \%$ of patients with fewer than 10 polyps and earlyonset CRC with no family history [12,14-16]. Furthermore, it has also been reported MAP patients having no polyps at the time of CRC diagnosis $[17,18]$.

Because of the observed overlap between the clinical phenotype of FAP/AFAP and MAP syndromes, the identification of the causative mutation has important implications for family management, allowing effective clinical surveillance and accurate genetic counseling. Moreover, the spectrum of mutations and the genotypephenotype correlations may have clinical impact and can be population-specific. Therefore, it is important to obtain genetic and clinical data from FAP/AFAP and MAP families in different populations.

The aim of this study was to conduct a comprehensive molecular analysis to determine the spectrum of point mutations and large genomic rearrangements (LGR) in the $A P C$ and MUTYH genes in a series of 23 Brazilian polyposis patients. This paper summarizes the mutation screening data and outlines the most cost-effective approach to detect $A P C$ and MUTYH mutations in Brazilian polyposis patients. In addition, we discuss the genotype-phenotype associations found in these families in the context of previously described data from the literature.

\section{Methods \\ Patients}

The study examined the Hereditary Colorectal Cancer Registry of A. C. Camargo Hospital (São Paulo, Brazil) [19], for families clinically suspected for FAP (> 100 colorectal adenomas) or AFAP/MAP (10-100 colorectal adenomas), enrolled between January 1998 and July 2011. Between 2010 and 2011, the genetic test was offered to forty registered unrelated polyposis families, from which 23 were available and willing to undergo genetic testing. Index patients were interviewed after providing informed consent and the family history was obtained through verbal report and, whenever possible, confirmed with clinical or pathological reports.

This study was performed in compliance with the Declaration of Helsinki and was approved by the ethics committee of A. C. Camargo Hospital (approval number: $1169 / 08-B)$. Once a mutation was identified in the index case, genetic counseling and molecular testing were offered to relatives.

\section{PCR and sequence analysis}

Mutation screening was performed by capillary sequencing of all coding exons of the APC [GenBank:NM_000038.5] and MUTYH [GenBank:NM_001128425.1] genes, including the intron-exon boundaries. Patients clinically suspected for FAP (> 100 polyps) were first screened for $A P C$ mutations, while patients with attenuated polyposis (< 100 polyps) were first screened for MUTYH mutations. Patients negative for the first screened gene were then screened for the remaining one.

Genomic DNA was obtained from leukocytes using a Puregene Genomic DNA Isolation Kit (Gentra Systems, Minneapolis, MN, USA) according to the manufacturer's instructions. PCR reactions used $25 \mathrm{ng}$ of template and $500 \mathrm{nM}$ of each primer in a final volume of $20 \mu \mathrm{l}$ with GoTaq Green Master Mix (Promega, Madison, WI, USA). Approximately $200 \mathrm{ng}$ of PCR-amplified fragments were purified with ExoSAP-IT (USB Corporation, Cleveland, $\mathrm{OH}, \mathrm{USA})$ and sequenced in both directions. Products were analyzed using an ABI 3130xl DNA sequencer (Applied Biosystems, Foster City, CA, USA) and the resulting sequences were aligned using CLCBio Genomics Workbench Software (Muehltal, Germany). The sequences of primers used for these analyses are available upon request. All mutations were confirmed in a second DNA sample. Mutations were recorded and referenced with respect to the cDNA sequence, using the nomenclature guidelines proposed by the Human Genome Sequence Variation Society (www.hgvs.org/mutnomen). 


\section{Allele-specific PCR}

Allele-specific PCR [20] was performed for MUTYH mutations to confirm the presence of two heterozygous alleles (compound heterozygosity). Primers were designed to be specific for the wild-type or mutated nucleotide of one of the MUTYH mutations. Sequencing of allelespecific PCR amplicons was performed to reveal the haplotype phase of the second mutation. PCR conditions and primers are available upon request.

\section{LGR screening}

Seven patients were selected for LGR screening using multiplex ligation-dependent probe amplification (MLPA), array-comparative genomic hybridization (aCGH), and duplex quantitative PCR (qPCR): five negative for $A P C$ or $M U T Y H$ point mutations, one with a novel $A P C$ missense variant, and one with a monoallelic $M U T Y H$ mutation. All experiments were performed in duplicate.

MLPA was performed using the SALSA P043-C1 APC Probemix kit (MRC Holland, Amsterdam, The Netherlands) following the manufacturer's protocol. PCR products were analyzed using an ABI 3130xl DNA sequencer (Applied Biosystems - Foster City, CA, USA), and gene dosage was calculated using Coffalyser V9.4 software (MRC Holland, Amsterdam, The Netherlands).

The aCGH platform used in this study was the SurePrint G3 Human CGH Microarray Kit $4 \times 180 \mathrm{k}$ (G4449A; Agilent Technologies, Santa Clara, CA, USA), which has an average resolution of $18 \mathrm{~kb}$, with 13 and three probes located within $A P C$ and $M U T Y H$, respectively. Briefly, samples were labeled with Cy3- or Cy5dCTPs by random priming. Purification, hybridization, and washing were performed as recommended by the manufacturer. Data extraction was conducted using Feature Extraction software (Agilent Technologies - Santa Clara, CA, USA). Genomic Workbench software (Agilent Technologies - Santa Clara, CA, USA) was applied to identify constitutive genomic imbalances using the statistical algorithm ADM-2, with a sensitivity threshold of 6.7, and a threshold $\log _{2}$ ratio of 0.4 for duplication and -0.4 for deletion.

Genomic alterations identified by MLPA and aCGH were validated using the duplex qPCR method previously established by our group [21].

\section{Variant analysis}

Mutations in the APC or MUTYH genes were considered deleterious if they: a) were classified as pathogenic in LOVD database; b) introduced a premature stop codon in the protein sequence (nonsense or frameshift mutation); c) occurred at donor or acceptor splice sites; or d) were whole-exon deletions or duplications. To establish the pathogenicity of one novel missense variant, web-based programs that predict the effect of an ami- no acid substitution were applied (SIFT, Polyphen, and MutationTaster). In addition, the frequency of this variant was assessed in 95 healthy Brazilian individuals.

\section{Clinical features and genotype-phenotype correlations}

The following clinical and pathological data were obtained from all families from the Hereditary Colorectal Cancer Registry of A. C. Camargo Hospital [19]: number of affected individuals, age at diagnosis, number of patients with extracolonic features, and primary sites of extracolonic tumors. The extent of polyposis burden (number of adenomas) was assessed for the index cases through colonoscopy records and/or pathological report from surgical specimens. For most family members this information was unavailable. Patients and their families were grouped according to the affected gene and the index case polyposis burden into five categories: group 1, $A P C$-mutated families with fewer than 100 colorectal adenomas (attenuated polyposis); group 2, $A P C$-mutated families with 100-1000 adenomas (intermediate polyposis); group 3, $A P C$-mutated families with more than 1000 adenomas (severe polyposis); group 4, MUTYHmutated families; and group 5, mutation-negative families.

Genotype-phenotype correlations in the three $A P C$ mutated groups were compared with those previously described, as reviewed by Nieuwenhuis and Vasen (2007) [22]. This review evaluated a large number of studies in FAP patients and proposed a categorization of the phenotypes according to the severity of the polyposis and the associated site of the $A P C$ mutation.

Statistical evaluation was performed using the Student's $t$-test using Prism 5 software (GraphPad, San Diego, CA, USA). Statistical significance was set at a $p$-value $<0.05$.

\section{Results}

Twenty-three Brazilian families with a clinical diagnosis of classical or attenuated polyposis were included in this study. The majority of the index cases (15) presented an intermediate or severe FAP phenotype ( $>100$ polyps) and 13 of them harbored an $A P C$ pathogenic mutation, while one patient was mutation-negative and one had a monoallelic MUTYH mutation. The remaining eight patients presented an attenuated polyposis burden $(<100$ polyps), among whom five carried biallelic mutations in the MUTYH gene, one carried a novel $A P C$ duplication of exons $1-3$, one presented a novel $A P C$ missense variant, and one was mutation-negative. Seven novel germline mutations (six pathogenic and one variant of unknown significance) were detected in this cohort, and two of them have been recently published by our group [21,23]. The APC and MUTYH mutation spectrum, including information about previous reports of the detected mutations, is summarized in Table 1. 


\section{$A P C$ mutations}

Fourteen pathogenic $A P C$ mutations were identified in this series: three small duplications, five small deletions, four nonsense mutations, one multiple exon duplication, and one whole-gene deletion. Six of them were novel mutations (Table 1). All patients presented distinct mutations, except for two unrelated probands that presented the hotspot mutation at codon 1309 (c.3927-3931delAAAGA; p.Glu1309Aspfs*4).

One patient (ID13) presented a novel missense $A P C$ variant of unknown significance: c.5365G > C (p.Val1789Leu). This patient was diagnosed with attenuated polyposis at the age of 56 years, presenting around 20 polyps at the time of clinical diagnosis. In silico studies using three different functional prediction programs (Polyphen, SIFT and MutationTaster), which all classified the p.Val1789Leu variant as having minimal or no effect on protein function, with the following scores: 0 (Polyphen); 0.30 (SIFT); 0.87 ( $P$ : 0.99, MutationTaster). Because the proband was the only affected member of the family, it was not possible to perform co-segregation analysis of the variant with the disease within the family; nevertheless, this variant was not detected in a control population of 95 healthy individuals.

In this series, two patients presented APC LGRs, identified by MLPA and/or aCGH and confirmed by gene dosage qPCR. Patient ID02 presented a 5.2-Mb deletion at 5q21.3-q22.3 that encompassed the entire APC gene and 19 additional genes, which have been previously published by our group [21]. The second patient (ID17) presented a duplication of $A P C$ exons 1-3 that was identified by MLPA (Figure 1A) and validated by duplex qPCR [21] (Figure 1B).

\section{MUTYH mutations}

Biallelic germline mutations in the MUTYH gene were identified in five patients, among whom two were homozygotes for the causative mutation and the remaining three were compound heterozygotes for two distinct

Table 1 APC and MUTYH mutation spectrum in Brazilian polyposis patients

\begin{tabular}{|c|c|c|c|c|c|c|}
\hline ID & Gene & Mutation & Exon & Type & \multicolumn{2}{|l|}{ Ref. $^{\text {a }}$ reported $\mathrm{N}$ times ${ }^{\mathrm{b}}$} \\
\hline \multicolumn{7}{|c|}{ Mutation-positive patients with > 100 polyps } \\
\hline 02 & $A P C$ & del 5q21.3-q22.3 (chr5:107916475-113079330 Hg19) & $1-15$ & gene deletion & Torrezan et al. [21] & 1 \\
\hline 04 & $A P C$ & c.856_859dupCATG (p.Glu287Alafs*2) & 8 & duplication & Current study & 0 \\
\hline 05 & $A P C$ & c.447dupC (p.Lys150GInfs*18) & 4 & duplication & Current study & 0 \\
\hline 23 & $A P C$ & c.4097dupC (p.Gln1367Serfs*8) & 15 & duplication & Current study & 0 \\
\hline 01 & $A P C$ & c.904C > T $($ p.Arg302*) & 8 & nonsense & Mandl et al. [24] & 22 \\
\hline 03 & $A P C$ & c.4348C > T (p.Arg1450*) & 15 & nonsense & Miyaki et al. [25] & 40 \\
\hline 06 & $A P C$ & c.3880-3881delCA (p.GIn1294Glyfs*6) & 15 & deletion & Miyaki et al. [25] & 1 \\
\hline 07 & $A P C$ & c.847C > T $($ p.Arg283*) & 8 & nonsense & Mandl et al. [24] & 49 \\
\hline 08 & $A P C$ & c.4099C > T (p.Gln1367*) & 15 & nonsense & Friedl and Aretz [26] & 8 \\
\hline 10 & $A P C$ & c.3050-3053delATGA (p.Asn1017Metfs*4) & 15 & deletion & Vandrovcová et al. [27] & 2 \\
\hline 11 & $A P C$ & c.3927-3931 delAAAGA (p.Glu1309Aspfs*4) & 15 & deletion & Miyoshi et al. [28] & 304 \\
\hline 14 & $A P C$ & c.4393-4394delAG (p.Ser1465Trpfs*3) & 15 & deletion & Miyoshi et al. [28] & 40 \\
\hline 21 & $A P C$ & c.3927-3931delAAAGA (p.Glu1309Aspfs*4) & 15 & deletion & Miyoshi et al. [28] & 304 \\
\hline 24 & MUTYH & c. $[1187 G>C] ;[=]$ (p.[Gln396Asp];[=]) & 13 & missense & Al-Tassan et al. [4] & 532 \\
\hline \multicolumn{7}{|c|}{ Mutation-positive patients with $<100$ polyps } \\
\hline 15 & MUTYH & c. $\left[348+33{ }^{*} 64+146\right.$ del4285insTA $] ;\left[348+33{ }^{*} 64+146\right.$ del4285insTA $]$ & $4-16$ & large deletion & Torrezan et al. [23] & 2 \\
\hline 13 & $A P C$ & c.5365G > C (p.Val1789Leu $)^{c}$ & 15 & missense & Current study & 0 \\
\hline 17 & $A P C$ & Exon 1-3 duplication & $1-3$ & large duplication & Current study & 0 \\
\hline \multirow[t]{2}{*}{16} & MUTYH & c.[536A > G]; [1147delC] (p.[Tyr179Cys]; [Ala385Profs*23]) & $7 ; 12$ & missense; & Al-Tassan et al. [4] & $532 ;$ \\
\hline & & & & deletion & Eliason et al. [29] & 71 \\
\hline \multirow[t]{2}{*}{18} & MUTYH & c.[389-1G > C]; [536A > G] (p.[Val130GlufsX98;p.(spl?)]; [Tyr179Cys]) & $\mathrm{i} 4 ; 7$ & splice site; & Olschwang et al. [30] & 2 \\
\hline & & & & missense & Al-Tassan et al. [4] & 532 \\
\hline 19 & MUTYH & c. [721C > T]; [721C > T] (p.[Arg241Trp]; [Arg241Trp]) & 9 & missense & Fleischmann et al. [31] & 11 \\
\hline \multirow[t]{2}{*}{447} & MUTYH & c.[536A > G]; [1227-1228dup] (p.[Tyr179Cys]; [Glu410Glyfs*43]) & $7 ; 13$ & missense; & Al-Tassan et al. [4]; & 506; \\
\hline & & & & duplication & Baglioni et al. [32] & 31 \\
\hline
\end{tabular}

a The following databases were consulted: LOVD: http://www.lovd.nl/2.0/; dbSNP: http://www.ncbi.nlm.nih.gov/projects/SNP/; and 1000 Genomes: http://www.1000genomes.org/; ${ }^{b}$ Number of times reported at LOVD database; ${ }^{c}$ Variant of unknown clinical significance. 
pathogenic variants. A monoallelic mutation was identified in one patient.

One patient (ID19) and her brother were homozygous for the p.Arg241Trp missense mutation, because of a consanguineous marriage between the parents. The second homozygous patient presented a deletion of exons 4-16 (c.348 + 33_*64 + 146del4285insTA) on both alleles, and stated having no known inbreeding in her family. This 4,285 bp deletion was the first LGR to be described in $M U T Y H$, recently published by us [23] and by an independent group that found this deletion in a French patient [33].

For the three patients harboring two distinct pathogenic variants (ID16, ID18, and ID447), we used allele-specific PCR to confirm the biallelic nature of the mutations. All cases presented the hotspot missense mutation p.Tyr179Cys in one allele accompanied by a second truncating mutation in the remaining allele (one deletion, one duplication, and one splice site mutation).

One patient (ID24) was a monoallelic carrier of the hotspot missense mutation p.Gly396Asp, and no other mutation could be identified.

\section{Clinical features}

Clinical records and verbal reports obtained from the 23 index patients and their relatives revealed 113 affected individuals among all families; their summarized clinical data are described in Table 2.

\section{Polyposis/CRC age at diagnosis}

Across the entire series, the average age at diagnosis and first symptoms of CRC and/or polyposis was 32.6 years (range 7-67 years). The mean age of onset in APC-positive families was 46.3 years (range 35-56) for group 1 (attenuated FAP); 35.7 (range 18-67) for group 2 (intermediate
FAP); and 29.2 (range 7-58) for group 3 (severe FAP). MAP families presented a mean age of 37.9 years (range 27-53 years); while the average age of onset in families with no identified mutation was 27.5 years (range 26-29 years). Comparison among the five groups revealed that the $A P C$-positive group 1, group 2, and MAP patients demonstrated a later age of onset compared with the severe FAP patients (group 3) (Figure 2).

\section{Extracolonic manifestations}

Extracolonic manifestations were reported in all $A P C$ mutated families (Table 2). Gastric and duodenal polyps (upper gastrointestinal polyps) were the most common extracolonic manifestations observed in these patients, and occurred in 11/14 families (79\%) and across all three APC groups. Osteomas were observed most often in the severe FAP patients (6/9), and epidermoid cysts/ lipomas occurred in the intermediate and severe FAP patients (5/13).

Desmoid tumors were observed in 8/14 APC-positive families $(57 \%)$ and were associated with different mutation sites, with only two of them occurring after codon 1444. Five families had more than one individual affected by desmoid tumors.

MAP families had fewer extracolonic manifestations: only one family presented upper gastrointestinal polyps and none presented desmoid tumors.

Regarding other tumor sites, papillary thyroid carcinoma appeared in one family of $A P C$ group 3; liver and breast cancers were reported in two families each: one from group 2 and one from group 3; uterine cancer was reported in one group 1 and one group 4 (MAP) family. Finally, lung, hematologic, brain, or skin cancer and melanoma were reported in one family each.

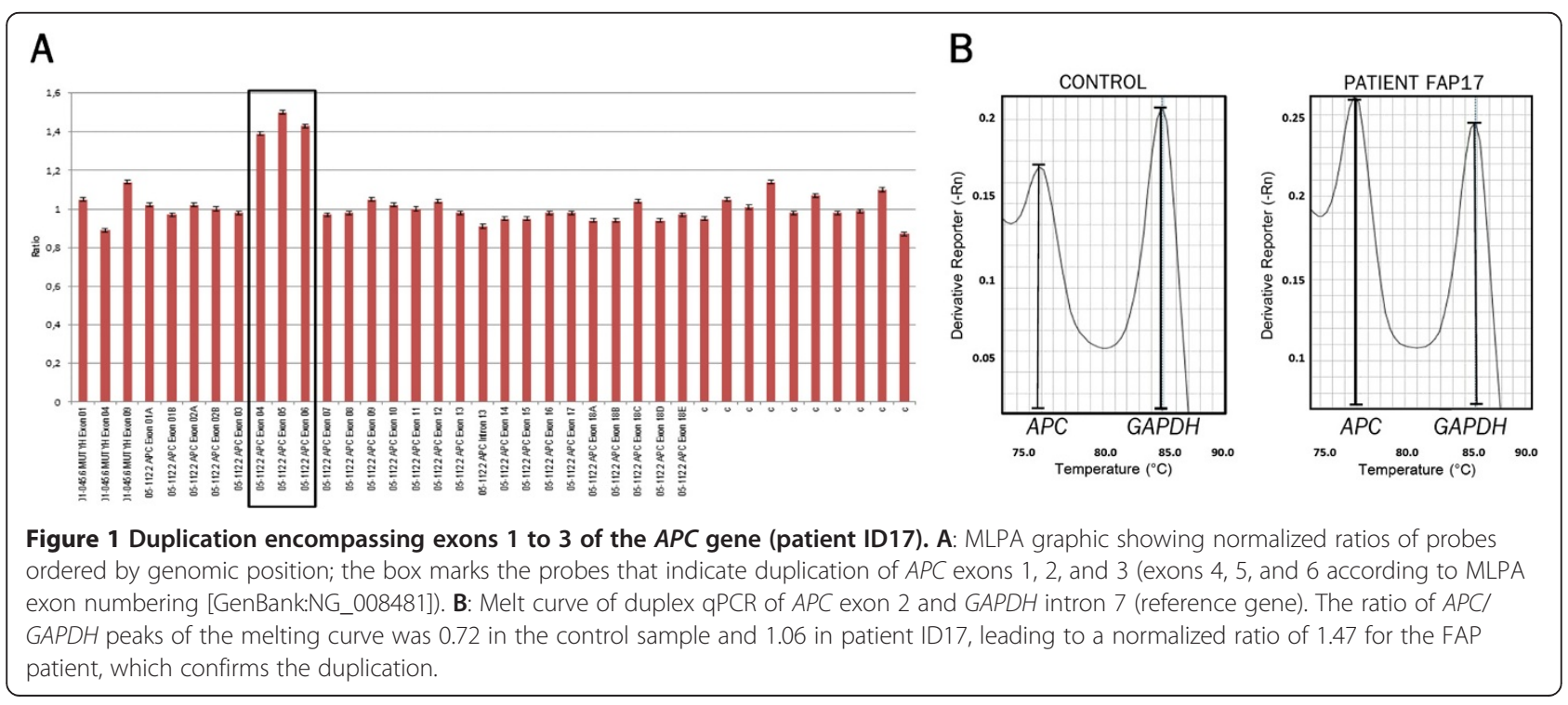


Table 2 Clinical features of the 23 Brazilian polyposis families

\begin{tabular}{|c|c|c|c|c|c|c|c|c|c|c|c|}
\hline \multirow[b]{2}{*}{ Family ID } & \multirow[b]{2}{*}{$\begin{array}{l}\text { Affected } \\
\text { codon }\end{array}$} & \multirow[b]{2}{*}{$\begin{array}{l}\text { Polyposis } \\
\text { burden }^{\mathrm{a}}\end{array}$} & \multirow[b]{2}{*}{$N^{b}$} & \multicolumn{2}{|c|}{ Age of onset } & \multicolumn{6}{|c|}{ Extracolonic Manifestations } \\
\hline & & & & Range & Mean & $\begin{array}{l}\text { Gastric } \\
\text { polyps }\end{array}$ & $\begin{array}{l}\text { Duodenal } \\
\text { polyps }\end{array}$ & Desmoid tumor(n) & Osteoma & $\begin{array}{l}\text { Epidermoid cysts/ } \\
\text { lipoma }\end{array}$ & Other tumor sites \\
\hline $\begin{array}{l}1 \text { - Attenuated } \\
\text { FAP }\end{array}$ & $A P C$ & & & $35-56$ & 46.3 & & & & & & \\
\hline ID13 & $1789^{c}$ & attenuated & 1 & 56 & 56 & yes & yes & no & no & NA & Uterus \\
\hline ID17 & Exon 1-3 dup & attenuated & 2 & $35-48$ & 41.5 & yes & No & no & no & NA & Lung \\
\hline $\begin{array}{l}2 \text { - Intermediate } \\
\text { FAP }\end{array}$ & $A P C$ & & & $18-67$ & 35.7 & & & & & & \\
\hline ID02 & Exon 1-15 del & intermediate & 5 & $40-44$ & 42 & yes & yes & no & no & NA & \\
\hline ID03 & 1450 & intermediate & 7 & $21-54$ & 34.2 & yes & yes & yes (2) & no & NA & Liver; Hematologic \\
\hline ID04 & 287 & intermediate & 14 & $18-44$ & 29.6 & no & no & no & no & NA & $\begin{array}{l}\text { Bilateral breast; Stomach; } \\
\text { BCC }\end{array}$ \\
\hline ID05 & 150 & intermediate & 18 & $29-67$ & 40 & yes & yes & yes (3) & no & yes & Breast; Melanoma \\
\hline 3 - Severe FAP & $A P C$ & & & $7-58$ & 29.2 & & & & & & \\
\hline ID01 & 302 & profuse & 5 & $14-27$ & 23.6 & yes & no & no & no & NA & Brain \\
\hline ID06 & 1294 & profuse & 11 & $20-35$ & 27.7 & yes & yes & yes (1) & yes & yes & \\
\hline ID07 & 283 & profuse & 8 & $27-58$ & 37 & yes & no & yes (2) & yes & yes & Liver \\
\hline ID08 & 1367 & profuse & 3 & $15-55$ & 35 & yes & yes & yes (1) & yes & NA & \\
\hline ID10 & 1017 & profuse & 15 & $7-55$ & 28.1 & no & no & yes (4) & yes & yes & Thyroid \\
\hline ID11 & 1309 & profuse & 3 & $30-40$ & 35 & yes & yes & no & yes & NA & \\
\hline ID14 & 1465 & profuse & 8 & $17-36$ & 26.5 & no & no & yes (2) & no & yes & \\
\hline ID21 & 1309 & profuse & 1 & 18 & 18 & yes & yes & no & yes & no & \\
\hline ID23 & 1367 & profuse & 1 & 22 & 22 & NA & NA & yes(1) & NA & NA & \\
\hline 4 - MAP & MUTYH & & & $27-53$ & 37.9 & & & & & & \\
\hline ID15 & Exon 4-16 del & attenuated & 2 & $42-44$ & 43 & no & no & no & no & NA & \\
\hline ID16 & $179 ; 385$ & attenuated & 2 & $30-53$ & 41.5 & yes & no & no & no & NA & Uterus \\
\hline ID18 & $130 ; 179$ & attenuated & 1 & 45 & 45 & no & no & no & no & NA & \\
\hline ID19 & $241 ; 241$ & attenuated & 2 & $27-31$ & 29 & no & no & no & no & NA & \\
\hline ID24 & $396 ;[=]$ & intermediate & 1 & 55 & 55 & NA & NA & no & NA & NA & \\
\hline ID447 & $179 ; 410$ & attenuated & 2 & $34-35$ & 34.5 & no & no & no & no & no & \\
\hline 5 - No Mutation & & & & $26-29$ & 27.5 & & & & & & \\
\hline ID20 & & attenuated & 1 & 26 & 26 & no & no & no & yes & no & \\
\hline ID22 & & intermediate & 1 & 29 & 29 & no & no & no & no & no & \\
\hline
\end{tabular}

a Polyposis burden of the index case. The remaining columns are based on all affective relatives with available clinical information; ${ }^{\mathrm{b}} \mathrm{N}=$ number of clinically affected family members; $\mathrm{BCC}=$ basal cell carcinoma; $\mathrm{NA}=$ data not available; ${ }^{\mathrm{C}}$ Variant of unknown clinical significance. 


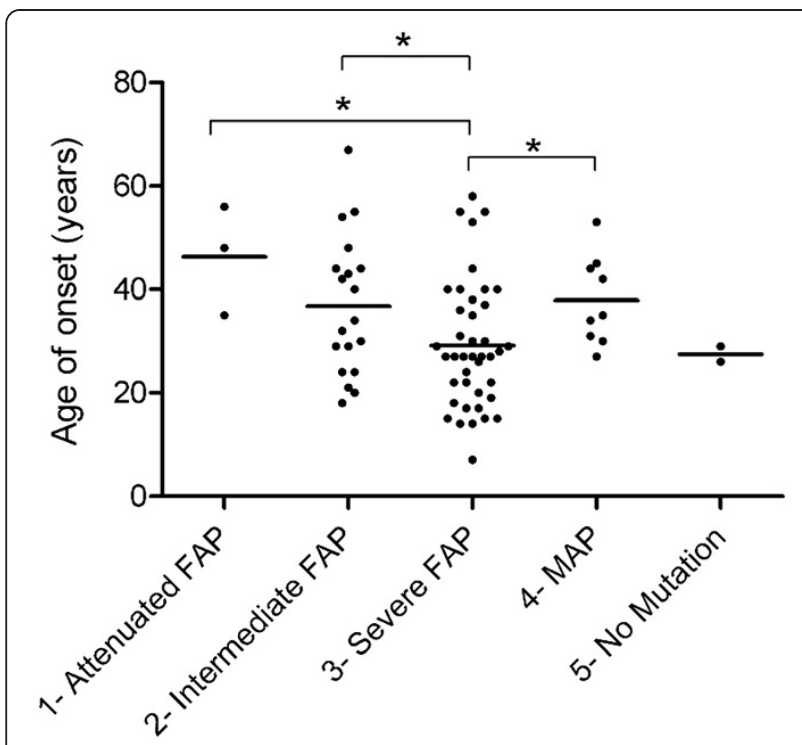

Figure 2 Age of onset per group. The graph shows the distribution and the mean (horizontal line) age of onset for each of the five defined groups. Groups 1, 2, and 4 patients had a significantly later age of onset than group 3 patients $(t=2.35 p=0.024 ; t=2.15 p=0.04$; $t=2.01 p=0.05$, respectively).

\section{Comparison with described APC genotype-phenotype correlations}

Genotype-phenotype correlations in polyposis syndromes have been evaluated in several studies, and a general association between the location of the mutation and the clinical manifestation has been observed, albeit with some inconsistencies [7,21,34-36]. Recently, Nieuwenhuis and Vasen (2007) [22] performed a meta-analysis and proposed categorization of the phenotypes into three degrees of polyposis severity and the associated site of $A P C$ mutation. Attenuated FAP was associated with mutations before codon 157, after codon 1595, and in the alternatively spliced region of exon 9; severe polyposis was related to mutations between codons 1250 and 1464; and an intermediate phenotype was associated with $A P C$ mutations located in the remaining sequence of the gene (Figure 3 ).

We compared the clinical and genetic data from our cohort with the $A P C$ codon limits defined by Nieuwenhuis and Vasen (2007) [22]. Figure 3A and B show the distribution of the polyposis phenotype of the index cases according to the location of their $A P C$ mutation, and compare it with the genotype-phenotype correlations previously proposed. Nine (64\%) of 14 FAP families with an $A P C$ pathogenic mutation presented the expected polyposis severity according to the location of the $A P C$ mutation, while the remaining five families exhibited discordant results from the anticipated phenotype. Nine families presented a profuse polyposis burden $(>1000$

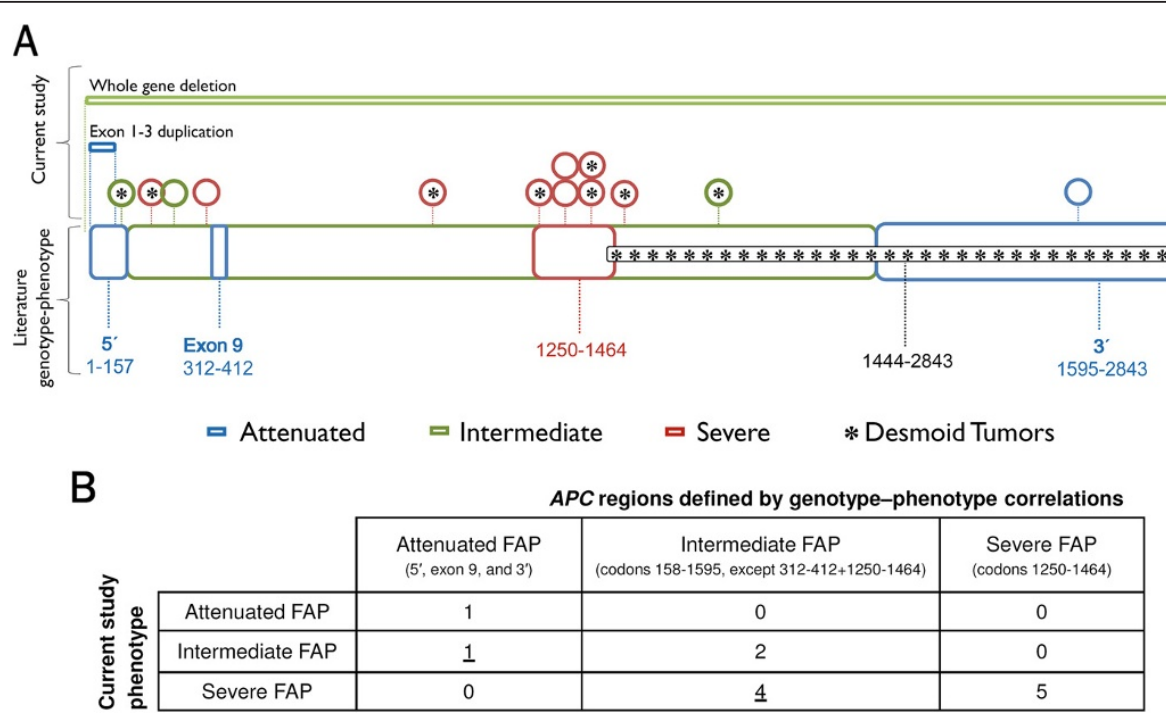

Figure 3 Genotype-phenotype correlation. A: Distribution of the polyposis phenotype of the index case and the presence of desmoid tumors along the APC gene. Schematic representation of the two large genomic rearrangements (top bars) and the 13 point mutations or small insertions/deletions (circles) identified in this series (including the variant of unknown significance - last circle). The asterisk inside the circles denotes patients with desmoid tumors. The lower, thick bar represents the APC regions defined by genotype-phenotype correlations proposed by Nieuwenhuis and Vasen (2007) [22]. Genotype-phenotype correspondence between our results and those previously published is indicated by concordant colors (blue/green/red/black). Numbers represent APC codons. B: Number of families presenting APC point mutations ( $N=13)$ according to the index case polyposis phenotype and the APC codon limits, showing that five individuals (underlined numbers) presented a polyposis burden different from that predicted. 
polyps) - two of them carried a mutation in codon 1309 , two in codon 1367, and one in codon 1294, while the four remaining patients carried mutations in codons usually associated with an intermediate number of polyps (codons 283, 302, 1017, and 1465) (Figure 3A and B).

\section{Particular phenotypes}

Two of the herein identified mutations presented a remarkably more aggressive phenotype than expected given their location and the phenotypes reported in the literature. The mutation c.447dupC (p.Lys150GlnfsX18), identified in family ID05, is located in exon 4; the 5 region of the $A P C$ gene is generally associated with attenuated polyposis and later age of onset. While the mean age of onset in this family (40 years old) was within the predicted range, the polyposis phenotype caused by this novel mutation was more aggressive than expected, since several members of the family presented more than 100 adenomatous polyps. Furthermore, three relatives had developed a desmoid tumor, usually not observed in patients with a mutation at the $5^{\prime}$ end of the $A P C$ gene.

An aggressive phenotypic expression was also observed for the mutation c.3050-3053delATGA (p.Asn1017MetfsX4), identified in family ID10 (Figure 4). Although the mutation is located in the region associated with an intermediate FAP phenotype, the proband presented a high number of polyps (>1000) at the age of 15, a desmoid tumor at the age of 20, and thyroid carcinoma and jaw keratocysts at 21 years. Her brother and seven cousins also developed polyps at early ages $(7,14,15,19,17,22$, and two at 29 years old). Desmoid tumors were described in another three relatives.

\section{Discussion}

This is the first report of a comprehensive mutational analysis and genotype-phenotype correlation in Brazilian polyposis families. Through direct sequencing of the APC and MUTYH genes, MLPA, aCGH, and duplex qPCR, we were able to identify pathogenic mutations in 20 of 23 index cases - a detection rate of $87 \%$. Of the remaining three patients, two were mutation-negative and one harbored a novel APC missense variant (p.Val1789Leu). Because of the lack of affected relatives for co-segregation analysis and the inconclusive results given by in silico analysis and control population screening, the clinical significance of this alteration is yet to be determined. Interestingly, a parallel study from our institution, performed in high risk cancer patients, revealed that this patient also presents a rare germline microdeletion of the PIP gene possibly associated with an increased cancer risk (Silva 2013, unpublished observations), suggesting that these two alterations may be acting in synergy.

The detection rate in polyposis patients from other populations varies markedly, ranging from 39 to $90 \%$; the variation reflects different selection criteria for testing and diverse sensitivity of screening strategies [4,27,37-40]. Our data reinforce the need to apply a combination of mutation-screening methods to detect the disease-causing mutation in polyposis patients efficiently. Most APC mutations previously described were identified with conventional methods, for instance denaturing high performance liquid chromatography or the protein truncation test, which can have a relatively low detection rate. Nowadays, the gold standard detection method for polyposis patients is direct DNA sequencing of all APC and MUTYH coding exons (including intron-exon boundaries), accompanied by screening for LGR, as was performed here.

The majority of mutations identified in our cohort were distinct, except for two families who shared the codon 1309 hotspot APC mutation and three families who presented the p.Tyr179Cys hotspot mutation in one of the MUTYH alleles. The absence of the commonly reported $A P C$ mutation at codon 1061, and the relatively low frequency of the hotspot mutations APC 1309, MUTYH p.Tyr179Cys, and p.Gly396Asp are consistent with the fact that Brazilian patients represent an admixed population, probably lacking a founder $A P C$ or $M U T Y H$ mutation.

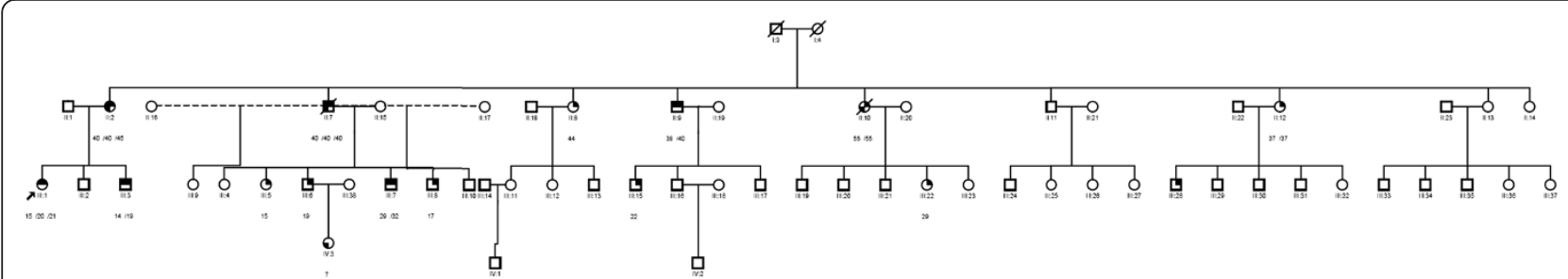

Figure 4 Family tree of ID10 family. This family harbored a truncating mutation at codon 1017 located in a region usually associated with an intermediate FAP phenotype. This mutation displayed an aggressive phenotypic expression: the proband (individual III:1, indicated by an arrow) presented her first polyposis symptoms at the age of 15, a desmoid tumor at age 20, and a thyroid carcinoma at age 21 . When available, the ages of onset are presented under each individual. Her brother (III:2) and six first cousins (III:5, 6, 7, 8, 15, and 22) also developed polyps at early ages (14 to 29 years old). The most prematurely affected was a second cousin (individual IV:3), who was diagnosed with polyps at the age of 7. Desmoid tumors were described in another three relatives: two uncles at the age of 40 (II:7 and II:9) and one cousin at 32 years old (III:7). 
The p.Tyr179Cys and p.Gly396Asp MUTYH mutations were identified in three families and one family, respectively, and corresponded to $44 \%$ of all mutated alleles identified in this gene (4/9). These are also the most prevalent mutations in populations of European origin, probably because of a founder effect, and account for approximately $80 \%$ of all reported mutant alleles [12]. A recent report described a screen for these two variants in 30 Brazilian patients with clinical phenotypes of MAP and FAP; 5/30 patients were identified as carrying one of these two hotspot mutations, and four of them were in a biallelic state [41]. However, because the entire coding sequence of MUTYH was not evaluated in all patients in this study, we cannot perform comparisons with the frequency found in our patients.

In our series, we could not identify a causative mutation in two index cases-one with attenuated polyposis and one with an intermediate polyposis phenotype. A possible explanation for the polyposis phenotype in these patients is the presence of unusual mutations in the $A P C$ or MUTYH genes, such as intron or promoter point mutations, epimutations or genetic mosaicism. In this sense, a recent study demonstrated that up to $8 \%$ of $A P C / M U T Y H$-negative polyposis patients presented a deep intronic $A P C$ variant that led to an aberrant transcript [42]. A second possibility is the existence of other susceptibility genes, and with the current possibility of screening all coding genes by next generation exome sequencing, it can be anticipated that novel polyposispredisposing genes will be identified.

Considering that this study is the first comprehensive analysis of $A P C$ and $M U T Y H$ mutations in Brazilian polyposis patients, we attempted to determine the most cost-effective approach to detect the causative mutation in this population. In patients presenting fewer than 100 polyps $(\mathrm{N}=8), 62 \%$ carried a biallelic mutation in the MUTYH gene. Among patients with more than 100 polyps (15 cases), three cases presented a mutation in $A P C$ exon 8 and eight cases (53\%) exhibited a mutation between codons 1017 and 1650 of $A P C$ exon 15. Interestingly, this initial region of exon 15 comprises only $16 \%$ of the coding sequence of $A P C$, yet presented a high mutation rate in our cohort. Therefore, based on our results, an optimized scheme for the molecular diagnosis of APC and MUTYH mutations in the Brazilian population might be obtained as follows: for patients presenting $>100$ polyps, codons 1017-1650 of $A P C$ exon 15 should be sequenced first, followed by exon 8 , and then the remaining $A P C$ exons; for patients presenting fewer than 100 polyps, MUTYH should be firstly screened. Because none of the studied MUTYH patients presented only the hotspot mutations p.Tyr179Cys or p.Gly396Asp, the whole gene should be sequenced, instead of undertaking an initial search for these variants, as recommended for other populations [18].
Genotype-phenotype correlations in polyposis syndromes are of great clinical interest, because they can contribute to better genetic counseling and simplify mutation screening. In several studies, an association between the location of the mutation and the clinical manifestations has been observed [7,20,27,34-36]. However, since several contradictions have also been reported [22], it remains unclear whether the genetic information should guide clinical decision-making, such as the extent of the prophylactic colectomy or the protocol for clinical surveillance [7,43-47].

Regarding the age at which clinical surveillance should begin, the established guidelines suggest that classical FAP patients should start endoscopic surveillance from the early teens, while AFAP and MAP families could start surveillance at age 18-20 [46]. Similar to the literature, our results demonstrated that severe FAP patients had an earlier age of onset (on average 10 years younger than AFAP or MAP patients). However, the most premature case in our series was a 7-year-old patient from a family with an $A P C$ mutation at codon 1017 - a region usually associated with an intermediate phenotype. A particularly aggressive phenotypic expression of this mutation was observed in this family; several relatives presented a high number of polyps (> 1000), an early age of onset, and desmoid tumors. This case demonstrates the importance of considering the family clinical history when planning the surveillance of other family members.

One of the most clinically important discrepancies observed in our study concerns desmoid tumors, which, even if histologically benign, can lead to life-threatening complications through their size and impingement on vital structures. Indeed, desmoid tumors represent the second leading cause of death in FAP patients $[46,48]$ and were identified at high frequency in our cohort, occurring in $57 \%(8 / 14)$ of $A P C$-mutated families. Although described as usually associated with mutations after codon 1444 [22], only two out of eight families affected by desmoid tumors in our study harbored mutations after this codon. In concordance with our findings, previous studies with large cohorts have also failed to confirm this association [49], or described different boundaries for the increased risk of these tumors, such as codon 1310 [50] or 1395 [35]. Furthermore, besides the location of $A P C$ mutations, several other risk factors are suggested to be related with desmoid tumor development, such as surgical trauma [51], pregnancy [52] and especially positive family history for desmoid tumors [49]. In this regard, the last appears to be the most important risk factor for our population, since five of eight families with desmoid tumors presented more than one relative affected by this tumor.

The differences observed in certain phenotypic features between our series and those of others may be 
because of our relatively small number of FAP and MAP families, may reflect some selection or data collection bias, or may be related to phenotypic peculiarities in this specific population. In this sense, the majority of FAP genotype-phenotype studies were performed in Europeans cohorts $[34-40,43,47,49]$ and the self-declared ethnic origin of most families from our study was also European (Portuguese, Italian and Spanish, mainly) - except from two Japanese and one Arabian families. However, it is important to highlight that Brazilians represent an extremely admixed population, with most individuals presenting some degree of African and Amerindian ancestry [53].

Furthermore, intra and interfamilial variations in the FAP phenotype are also well documented in other populations, and it is likely that modifying genes and environmental factors, as well as functional polymorphisms of the normal $A P C$ allele, play a crucial role in determining the clinical course of disease [54,55]. In this regard, the different genetic background and/or environmental factors of our population could be responsible for the phenotypic differences observed in our study. For instance, in our series, desmoid tumors were much more prevalent in $A P C$-mutated patients (57\%) than in others previous studies $(10-15 \%)[22,49,54]$, indicating that perhaps our set of patients represents a distinct group regarding this extracolonic feature.

Finally, the lack of a clear phenotypic expression of the mutations identified in our study complicates clinical predictions based on knowledge of the mutation site, and as a result, we can make no specific surveillance and management recommendations for the Brazilian population. In order to accomplish that, larger studies need to be carried out. Instead, we recommend that clinical decisions regarding an individual patient should not be based strictly on the genotype, but mainly on the colonic phenotype and family clinical history.

\section{Conclusions}

In this comprehensive investigation of the $A P C$ and MUTYH mutation spectrum in Brazilian polyposis patients, we identified a high frequency of germline mutations, allowing the identification of several novel pathogenic variants and the proposal of a cost-effective screening approach for this population. Notably, a significant number of $A P C$ mutation-positive families were not consistent with predicted genotype-phenotype correlations, and this should be taken into consideration for genetic counseling and patient management of our population.

\section{Competing interests}

The authors declare that they have no competing interests.

\section{Authors' contributions}

GTT, DMC, and BMR conceived and designed experiments. GTT, FCCS, ACVK, and DMC performed and analyzed experiments. EMMS, MIA, SAJ, and BMR assessed clinical data and selected patients. BMR and DMC contributed reagents/materials/analysis tools. GTT, FCCS, ACVK, BMR, and DMC wrote/ edited the paper. All authors have read and approved the final manuscript.

\section{Acknowledgments}

The authors acknowledge the patients and families for their collaboration, the staff of the Nucleic Acid Bank of A. C. Camargo Hospital (São Paulo, Brazil) for sample processing, Israel Gomy (CIPE - A. C. Camargo Hospital, São Paulo, Brazil) for patient referral and Bianca C. G. Lisboa (Molecular Diagnostic Lab - A. C. Camargo Hospital, São Paulo, Brazil) for guidance in establishing the sequencing protocols.

\section{Funding}

This work was supported by the National Institute of Science and Technology in Oncogenomics (INCITO) (FAPESP: 2008/57887-9) and the European Union FP7 Genetic study of Common Hereditary Bowel Cancers in Hispania and the Americas (CHIBCHA) project.

\section{Author details}

'Laboratory of Genomics and Molecular Biology, A. C. Camargo Hospital, São Paulo, SP, Brazil. ${ }^{2}$ National Institute of Science and Technology in Oncogenomics (INCITO), São Paulo, SP, Brazil. ${ }^{3}$ Colorectal Tumors Department, A. C. Camargo Hospital, São Paulo, SP, Brazil. ${ }^{4}$ Laboratory of Structural Genomics, A. C. Camargo Hospital, São Paulo, SP, Brazil.

${ }^{5}$ Oncogenetics Department, A. C. Camargo Hospital, São Paulo, SP, Brazil. ${ }^{6}$ Barretos Cancer Hospital, Pio XII Foundation, Rua Dona Adma Jafet 74 cj. 145, CEP: 01308-050, São Paulo, SP, Brazil. 'Laboratory of Genomics and Molecular Biology, International Center of Research - A. C. Camargo Hospital, Rua Taguá, 440, CEP: 01508-010, São Paulo, SP, Brazil.

Received: 11 December 2012 Accepted: 27 March 2013

Published: 5 April 2013

\section{References}

1. Gardner EJ, Burt RW, Freston JW: Gastrointestinal Polyposis: Syndromes and Genetic Mechanisms. West J Med 1980, 132:488-499.

2. Leppert M, Dobbs M, Scambler P, O'Connell P, Nakamura Y, Stauffer D, Woodward S, Burt R, Hughes J, Gardner E: The gene for familial polyposis coli maps to the long arm of chromosome 5. Science 1987, 238:1411-1413.

3. Knudsen AL, Bisgaard ML, Bülow S: Attenuated familial adenomatous polyposis (AFAP). A review of the literature. Fam Cancer 2003, 2:43-55.

4. Al-Tassan N, Chmiel NH, Maynard J, Fleming N, Livingston AL, Williams GT, Hodges AK, Davies DR, David SS, Sampson JR, Cheadle JP: Inherited variants of MYH associated with somatic G:C > T:A mutations in colorectal tumors. Nat Genet 2002, 30:227-232.

5. Kinzler KW, Nilbert MC, Su LK, Vogelstein B, Bryan TM, Levy DB, Smith KJ, Preisinger AC, Hedge P, McKechnie D, Finniea R, Matrkam A, Groffen J, Boguski MS, Altschul SF, Horii A, Ando H, Miyoshi Y, Miki Y, Nishisho I, Nakamura Y: Identification of FAP locus genes from chromosome 5q21. Science 1991, 253:661-665.

6. Nishisho I, Nakamura Y, Miyoshi Y, Miki Y, Ando H, Horii A, Koyama K, Utsunomiya J, Baba S, Hedge P: Mutations of chromosome 5 q21 genes in FAP and colorectal cancer patients. Science 1991, 253:665-669.

7. Soravia C, Berk T, Madlensky L, Mitri A, Cheng H, Gallinger S, Cohen Z, Bapat B: Genotype-phenotype correlations in attenuated adenomatous polyposis coli. Am J Hum Genet 1998, 62:1290-1301.

8. Young J, Simms LA, Tarish J, Buttenshaw R, Knight N, Anderson GJ, Bell A, Leggett B: A family with attenuated familial adenomatous polyposis due to a mutation in the alternatively spliced region of APC exon 9. Hum Mutat 1998, 11:450-455.

9. Davidson S, Leshanski L, Rennert G, Eidelman S, Amikam D: Maternal mosaicism for a second mutational event-a novel deletion-in a familial adenomatous polyposis family harboring a new germ-line mutation in the alternatively spliced-exon 9 region of APC. Hum Mutat 2002, 19:83-84. 
10. Venesio T, Balsamo A, Agostino VGD, Ranzani GN: MUTYH-associated polyposis (MAP), the syndrome implicating base excision repair in inherited predisposition to colorectal tumors. Front Oncol 2012, 2(83):1-9.

11. Out AA, Tops CMJ, Nielsen ÃM, Weiss MM, van Minderhout IJ, Fokkema IF, Buisine MP, Claes K, Colas C, Fodde R, Fostira F, Franken PF, Gaustadnes M, Heinimann K, Hodgson SV, Hogervorst FB, Holinski-Feder E, LagerstedtRobinson K, Olschwang S, van den Ouweland AM, Redeker EJ, Scott RJ, Vankeirsbilck B, Grønlund RV, Wijnen JT, Wikman FP, Aretz S, Sampson JR, Devilee P, den Dunnen JT, Hes FJ: Leiden Open Variation Database of the MUTYH Gene Human Mutation. Hum Mutat 2010, 31:1205-1215.

12. Aretz S, Genuardi M, Hes FJ: Clinical utility gene card for: MUTYHassociated polyposis (MAP), Autosomal recessive colorectal adenomatous polyposis, Multiple colorectal adenomas, Multiple adenomatous polyps (MAP) - update 2012. Eur J Hum Genet 2012, 8:1-4.

13. Sampson JR, Jones S, Dolwani S, Cheadle JP: MutYH (MYH) and colorectal cancer. Biochem Soc Trans 2005, 33:679-683.

14. Sieber OM, Lipton L, Crabtree M, Heinimann K, Fidalgo P, Phillips RK, Bisgaard ML, Orntoft TF, Aaltonen LA, Hodgson SV, Thomas HJ, Tomlinson IP: Multiple Colorectal Adenomas, Classic Adenomatous Polyposis and Germ-Line Mutations in MYH. N Eng J Med 2003, 9:791-799.

15. Filipe B, Baltazar C, Albuquerque C, Fragoso S, Lage P, Vitoriano I, Mão De Ferro S, Claro I, Rodrigues P, Fidalgo P, Chaves P, Cravo M, Nobre Leitão C: APC or MUTYH mutations account for the majority of clinically wellcharacterized families with FAP and AFAP phenotype and patients with more than 30 adenomas. Clin Genet 2009, 76:242-255.

16. Casper M, Plotz G, Juengling B, Zeuzem S, Lammert F, Raedle J: MUTYH hotspot mutations in unselected colonoscopy patients. Colorectal Dis 2012, 14:238-244.

17. Nielsen M, Morreau H, Vasen HFA, Hes FJ: MUTYH-associated polyposis (MAP). Crit Rev Oncol Hematol 2011, 79(1):1-16.

18. Sampson JR, Dolwani S, Jones S, Eccles D, Ellis A, Evans DG, Frayling I, Jordan S, Maher ER, Mak T, Maynard J, Pigatto F, Shaw J, Cheadle JP: Autosomal recessive colorectal adenomatous polyposis due to inherited mutations of MYH. Lancet 2003, 362:39-41.

19. Santos EMM, Ferreira FO, Aguiar S, Nakagawa WT, Lopes A, Medeiros A, Rossi BM: Familial Adenomatous Polyposis: Data from the Hereditary Colorectal Cancer Registry (HCCR). Applied Cancer Research 2008, 28(1):17-23.

20. Newton CR, Graham A, Heptinstal LE, Powell SJ, Summers C, Kalsheker N, Smith JC, Markham AF: Analysis of any point mutation in DNA. The amplification refractory mutation system (ARMS). Nucleic Acids Res 1989, 17:2503-2516

21. Torrezan GT, Silva FC D, Krepischi ACV, Dos Santos EM, Rossi BM, Carraro DM: A novel SYBR-based duplex qPCR for the detection of gene dosage: detection of an APC large deletion in a familial adenomatous polyposis patient with an unusual phenotype. BMC Med Genet 2012, 13:55.

22. Nieuwenhuis MH, Vasen HFA: Correlations between mutation site in APC and phenotype of familial adenomatous polyposis (FAP): A review of the literature. Crit Rev Oncol Hematol 2007, 61:153-161.

23. Torrezan GT, Silva FC D, Krepischi ACV, Santos EM, Ferreira Fde O, Rossi BM, Carraro DM: Breakpoint characterization of a novel large intragenic deletion of MUTYH detected in a MAP patient: Case report. BMC Med Genet 2011, 12:128.

24. Mandl M, Paffenholz R, Friedl W, Caspari R, Sengteller M, Propping P. Frequency of common and novel inactivating APC mutations in 202 families with familial adenomatous polyposis. Hum Mol Genet 1994, 3(1):181-184.

25. Miyaki M, Konishi M, Kikuchi-Yanoshita R, Enomoto M, Igari T, Tanaka K, Muraoka M, Takahashi H, Amada Y, Fukayama M, Maeda Y, Iwama T, Mishima Y, Mori T, Koike M: Characteristics of somatic mutation of the adenomatous polyposis coli gene in colorectal tumors. Cancer Res 1994, 54(11):3011-3020.

26. Friedl W, Aretz S: Familial adenomatous polyposis: experience from a study of 1164 unrelated german polyposis patients. Hered Cancer Clin Pract 2005, 3(3):95-114.

27. Vandrovcová J, Štekrová J, Kebrdlová V, Kohoutová M: Molecular Analysis of the APC and MYH Genes in Czech Families Affected by FAP or Multiple Adenomas: 13 Novel Mutations. Hum Mutat 2004, 23:397-404.

28. Miyoshi $Y$, Ando H, Nagase H, Nishisho I, Horii A, Miky Y, Mori T, Utsunomiya J, Baba S, Petersen G, Hamilton SR, Kinzler KW, Vogelstein B, Nakamura Y: Germ-line mutations of the APC gene in 53 familial adenomatous polyposis patients. Proc Natl Acad Sci 1992, 89:4452-4456.
29. Eliason K, Hendrickson BC, Judkins T, Norton M, Leclair B, Lyon E, Ward B, Noll W, Scholl T: The potential for increased clinical sensitivity in genetic testing for polyposis colorectal cancer through the analysis of $\mathrm{MYH}$ mutations in North American patients. J Med Genet 2005, 42(1):95-96.

30. Olschwang S, Blanché H, de Moncuit C, Thomas G: Similar colorectal cancer risk in patients with monoallelic and biallelic mutations in the MYH gene identified in a population with adenomatous polyposis. Genet Test 2007, 11(3):315-320.

31. Fleischmann C, Peto J, Cheadle J, Shah B, Sampson J, Houlston RS: Comprehensive analysis of the contribution of germline MYH variation to early-onset colorectal cancer. Int J Cancer 2004, 109(4):554-558.

32. Baglioni S, Melean G, Gensini F, Santucci M, Scatizzi M, Papi L, Genuardi M: A kindred with MYH-associated polyposis and pilomatricomas. Am J Med Genet A 2005, 134A(2):212-214.

33. Rouleau E, Zattara H, Lefol C, Noguchi T, Briaux A, Buecher B, Bourdon V, Sobol H, Lidereau $\mathrm{R}$, Olschwang $\mathrm{S}$ : First large rearrangement in the MUTYH gene and attenuated familial adenomatous polyposis syndrome. Clin Genet 2011, 80:301-303.

34. Bunyan DJ, Shea-Simonds J, Reck C, Finnis D, Eccles DM: Genotypephenotype correlations of new causative APC gene mutations in patients with familial adenomatous polyposis. J Med Genet 1995, 32:728-731.

35. Wallis YL, Morton DG, McKeown CM, Macdonald F: Molecular analysis of the APC gene in 205 families: extended genotype-phenotype correlations in FAP and evidence for the role of APC amino acid changes in colorectal cancer predisposition. J Med Genet 1999, 36:14-20.

36. Groves C, Lamlum H, Crabtree M, Williamson J, Taylor C, Bass S, CuthbertHeavens D, Hodgson S, Phillips R, Tomlinson I: Mutation cluster region, association between germline and somatic mutations and genotypephenotype correlation in upper gastrointestinal familial adenomatous polyposis. Am J Pathol 2002, 160:2055-2061.

37. Gómez-fernández N, Castellví-bel S, Fernández-rozadilla C, Balaguer F, Muñoz J, Madrigal I, Milà M, Graña B, Vega A, Castells A, Carracedo A, Ruiz-Ponte C: Molecular analysis of the APC and MUTYH genes in Galician and Catalonian FAP families: a different spectrum of mutations? BMC Med Genet 2009, 10:1-12.

38. Fostira F, Thodi G, Sandaltzopoulos R, Fountzilas G, Yannoukakos D: Mutational spectrum of APC and genotype-phenotype correlations in Greek FAP patients. Mol Biol 2010, 10:389.

39. Rivera B, Gonzalez S, Sánchez-Tomé E, Blanco I, Mercadillo F, Letón R, Benítez J, Robledo M, Capellá G, Urioste M: Clinical and genetic characterization of classical forms of familial adenomatous polyposis: a Spanish population study. Ann Oncol 2011, 22(4):903-909.

40. Kanter-Smoler G, Fritzell K, Rohlin A, Engwall Y, Hallberg B, Bergman A, Meuller J, Grönberg H, Karlsson P, Björk J, Nordling M: Clinical characterization and the mutation spectrum in Swedish adenomatous polyposis families. BMC Med 2008, 6:1-14.

41. Pitroski CE, Cossio SL, Koehler-Santos P, Graudenz M, Prolla JC, Ashton-Prolla $P$ : Frequency of the common germline MUTYH mutations p.G396D and p.Y179C in patients diagnosed with colorectal cancer in Southern Brazil. Int J Colorectal Dis 2011, 26(7):841-846.

42. Spier I, Horpaopan S, Vogt S, Uhlhaas S, Morak M, Stienen D, Draaken M, Ludwig M, Holinski-Feder E, Nöthen MM, Hoffmann P, Aretz S: Deep Intronic APC Mutations Explain a Substantial Proportion of Patients with Familial or Early-Onset. Hum Mutat 2012, 33:1-6.

43. Newton K, Mallinson E, Bowen J, Lalloo F, Clancy T, Hill J, Evans DG: Genotype - phenotype correlation in colorectal polyposis. Clin Genet 2011, 81(6):1-11.

44. Vasen HF, van der Luijt RB, Slors JF, Buskens E, de Ruiter P, Baeten CG, Schouten WR, Oostvogel HJ, Kuijpers JH, Tops CM, Meera KP: Molecular genetic tests as a guide to surgical management of familial adenomatous polyposis. Lancet 1996, 348:433-435.

45. Wu JS, Paul P, MCGannon E, Church JM: APC genotype, polyp number, and surgical options in familial adenomatous polyposis. Ann Surg 1998, 227:57-62.

46. Vasen HFA, Möslein G, Alonso A, Aretz S, Bernstein I, Bertario L, Blanco I, Bülow S, Burn J, Capella G, Colas C, Engel C, Frayling I, Friedl W, Hes FJ, Hodgson S, Järvinen H, Mecklin JP, Møller P, Myrhøi T, Nagengast FM, Parc Y, Phillips R, Clark SK, de Leon MP, Renkonen-Sinisalo L, Sampson JR, Stormorken A, Tejpar S, Thomas HJ, Wijnen J: Guidelines for the clinical management of familial adenomatous polyposis (FAP). Gut 2008, 57:704-713. 
47. Friedl W, Caspari R, Sengteller M, Uhlhaas S, Lamberti C, Jungck M, Kadmon M, Wolf M, Fahnenstich J, Gebert J, Möslein G, Mangold E, Propping P: Can APC mutation analysis contribute to therapeutic decisions in familial adenomatous polyposis? Experience from 680 FAP families. Gut 2001, 48:515-521.

48. Half E, Bercovich D, Rozen P: Familial adenomatous polyposis. Orphanet $J$ Rare Dis 2009, 4(22):1-23.

49. Nieuwenhuis MH, De Vos Tot Nederveen Cappel W, Botma A, Nagengast FM, Kleibeuker JH, Mathus-Vliegen EM, Dekker E, Dees J, Wijnen J, Vasen HF: Desmoid tumors in a dutch cohort of patients with familial adenomatous polyposis. Clin Gastroenterol Hepatol 2008, 6(2):215-219.

50. Bertario L, Russo A, Sala P, Eboli M, Giarola M, D'amico F, Gismondi V, Varesco L, Pierotti MA, Radice P: Genotype and phenotype factors as determinants of desmoid tumors in patients with familial adenomatous polyposis. Int I Cancer 2001, 95(2):102-107.

51. Gurbuz AK, Giardiello FM, Petersen GM, Krush AJ, Offerhaus GJ, Booker SV, Kerr MC, Hamilton SR: Desmoid tumours in familial adenomatous polyposis. Gut 1994, 35:377-381.

52. Clark SK, Neale KF, Landgrebe JC, Phillips RK: Desmoid tumours complicating familial adenomatous polyposis. Br J Surg 1999, 86:1185-1189.

53. Pena SDJ, Bastos-Rodrigues L, Pimenta JR, Bydlowski SP: DNA tests probe the genomic ancestry of Brazilians. Braz J Med Biol Res 2009, 42(10):870-876.

54. Sturt NJ, Gallagher MC, Bassett P, Philp CR, Neale KF, Tomlinson IP, Silver AR, Phillips RK: Evidence for genetic predisposition to desmoid tumours in familial adenomatous polyposis independent of the germline APC mutation. Gut 2004, 53(12):1832-1836.

55. Crabtree MD, Tomlinson IP, Hodgson SV, Neale K, Phillips RK, Houlston RS: Explaining variation in familial adenomatous polyposis: relationship between genotype and phenotype and evidence for modifier genes. Gut 2002, 51(3):420-423.

doi:10.1186/1750-1172-8-54

Cite this article as: Torrezan et al: Mutational spectrum of the APC and MUTYH genes and genotype-phenotype correlations in Brazilian FAP, AFAP, and MAP patients. Orphanet Journal of Rare Diseases 2013 8:54.

\section{Submit your next manuscript to BioMed Central and take full advantage of:}

- Convenient online submission

- Thorough peer review

- No space constraints or color figure charges

- Immediate publication on acceptance

- Inclusion in PubMed, CAS, Scopus and Google Scholar

- Research which is freely available for redistribution 